\title{
Environmental protection against the influence of the mechanical assembly section
}

\author{
German Pachurin ${ }^{1,2}$, Mariia Mukhina ${ }^{2, *}$, Zhanna Smirnova $^{2}$, Olga Vaganova $^{2}$, and Tatyana \\ Tsapina $^{3}$ \\ ${ }^{1}$ Nizhny Novgorod State Technical University n.a. R.E. Alekseev, 24, Minin str., 603950, Nizhny \\ Novgorod, Russia \\ ${ }^{2}$ Kozma Minin Nizhny Novgorod State Pedagogical University, 1, Ulyanova str., 603950, Nizhny \\ Novgorod, Russia \\ ${ }^{3}$ National Research Lobachevsky State University of Nizhny Novgorod, 23, Gagarin pr., 603950, \\ Nizhny Novgorod, Russia
}

\begin{abstract}
The article describes the solution to the problem of environmental protection from the impact of the machine assembly department of a shipbuilding production in the Upper Volga basin. The purpose of this work is to study the pollution sources and to design an engineering protection for the atmosphere from this impact, as well as the economic justification of the proposed measures. The problem of environmental protection is particularly relevant in industrial manufacturing. Pollutants have a harmful effect on the environment and especially on people working for heavy industry. Therefore, engineering protection of workers during the production is an urgent task. In this work, the mass of harmful substance emissions was determined, their concentration was calculated and the maximum permissible concentrations were identified. The calculation of the required purification from all contaminations of the machine assembly department was performed. The height of the release point above the ground is calculated. Based on the calculations, the necessary equipment was selected and an aerodynamic calculation of the exhaust ventilation system was performed. The amount of prevented economic damage due to the implementation of the designed environmental measures for the machine assembly department of the shipbuilding industry was determined.
\end{abstract}

\section{Introduction}

Environmental pollution is a global problem of the present time, which is regularly discussed in the news and scientific communities [1,2]. A great number of international organizations have been created to combat the deterioration of natural conditions. Scientists have long been sounding the alarm about the inevitability of an environmental disaster in the very near future [3-5].

Most negative environmental consequences of human activity cause atmosphere change - its physical and chemical composition. Emissions from industrial enterprises, energy

\footnotetext{
* Corresponding autohr: mariyamuhina@yandex.ru
} 
systems, and transport into the atmosphere, water bodies and soil have reached such proportions that in some areas of the world pollution levels significantly exceed acceptable health standards. This leads to an increase in the number of people suffering from chronic bronchitis, asthma, allergies, ischemia, and cancer, especially among the urban population [6,7]. Man-made impacts on the atmosphere have caused such global changes as the "greenhouse effect", ozone layer depletion, and acid rain. Currently, the volume of air emissions in the world has increased dramatically and amounts to many millions of tons, which exceeds the ability limits of the atmosphere to self-purify $[8,9]$. The environmental situation is particularly unfavourable in cities where the largest industrial facilities are located [10].

Industrial enterprises are serious sources of environmental pollution, as well as a source of negative impact on the health of industrial enterprises' employees engaged in the production process [11-15]. As a result of the increase in the production processes of the shipyard, it is necessary to monitor the quality of environmental protection and the company's employees through the timely design of the engineering protection system.

Therefore, engineering protection of people working in the plant conditions of the machine assembly department is relevant.

The purpose of this work is to study the sources of contamination of the machine assembly department and to design engineering protection of the atmosphere from its impact.

The research objectives are to identify and analyse the sources of pollution from the machine assembly department, to develop engineering protection, to justify the economic effect of the environmental protection measures introduction.

The machine shop is intended for performing machine repair work, machining of parts to be processed after surfacing, electroplating and other types of work. In the machine assembly department, harmful emissions of oil and emulsifier vapours, dust, wastewater, as well as waste intended for general and underground disposal are generated during production activities.

The main sources of atmospheric pollution are flat-grinding machines; round-grinding machines; machines for sharpening saws, drills; paint booths; dryer tables. As a result of the equipment's operation, dust, oil vapour and emulsifier are released into the atmosphere.

The concentration of harmful chemicals and dust in the air of the working area and the exposure time have a decisive influence on the damage degree to the human body. Therefore, the development of engineering protection is one of the most important tasks to ensure safe work practices.

\section{Methods}

The study was conducted based on the machine assembly department of the mechanical workshop of the shipbuilding plant in the Upper Volga basin. Mathematical calculations were used to determine the mass of harmful substance emissions from the machine assembly department into the atmosphere, their concentration was calculated and the maximum permissible concentrations for each of them were identified. After that, the emission of various pollutants through the exhaust system of toxic gases was determined, and the norms and conditions for their release were calculated. Based on the calculations, the necessary equipment was selected that will provide the necessary degree of protection from harmful effects on the atmosphere. 


\section{Results}

The quality of air in the working area of industrial enterprises, in open areas and outside of them is becoming an increasingly important factor determining the human health. In the machine assembly department, harmful emissions of oil and emulsifier vapours, dust, wastewater, as well as waste intended for general and underground disposal are generated during production activities. Two release points are provided for purifying the machine assembly department [16]. The source of contamination at the first point is machines, and the second point of release is characterized by the release of solvent vapours and paint aerosol.

To develop a protection system against harmful substances, it is necessary to calculate the amount of harmful substances released into the atmosphere. The following issues were identified: sources of pollutants, the name of the pollutant, total gross emission of i-th pollutant through the release points, the total maximum one-time emission of $i$-th pollutant through the release points, the concentration of the $\mathrm{i}$-th pollutant emission and maximum permissible concentration (MРС $\mathrm{OT}$ ).

The data is presented in table 1 .

Table 1. Calculation data of air emissions into the atmosphere.

\begin{tabular}{|c|c|c|c|c|c|c|c|}
\hline 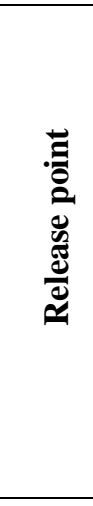 & 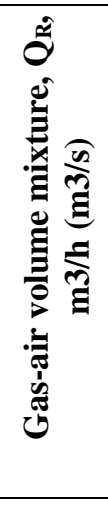 & 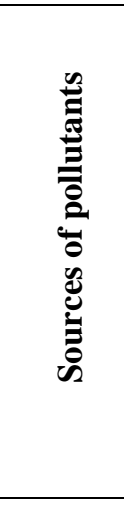 & 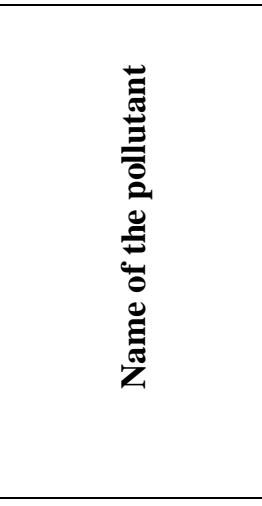 & 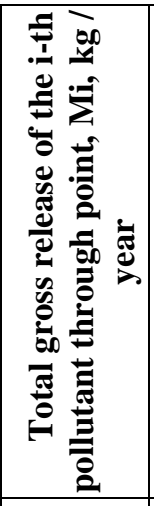 & 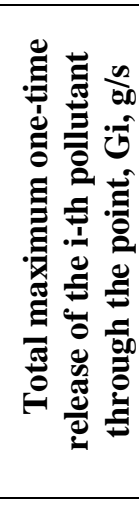 & 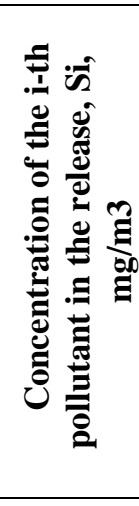 & 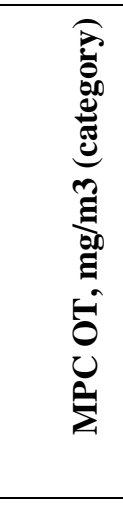 \\
\hline \multirow[b]{2}{*}{1} & \multirow{2}{*}{$\begin{array}{l}18100 \\
(5,03)\end{array}$} & \multirow{2}{*}{ Machin } & Abrasive dust & 2818,26 & 0,57 & 113,37 & \begin{tabular}{|l|}
0,04 \\
(III cat)
\end{tabular} \\
\hline & & & $\begin{array}{l}\text { Oil vapour and } \\
\text { emulsifier }\end{array}$ & 19,43 & 0,00061 & 0,121 & 5,0 \\
\hline \multirow{4}{*}{2} & \multirow{4}{*}{$\begin{array}{l}6480 \\
(1,8)\end{array}$} & \multirow{4}{*}{$\begin{array}{l}\text { Paint } \\
\text { and } \\
\text { dryer } \\
\text { booth }\end{array}$} & Butyl acetate & 129,68 & 0,023 & 12,78 & $\begin{array}{l}0,1 \\
\text { (IV cat.) }\end{array}$ \\
\hline & & & Acetone & 363,09 & 0,085 & 47,22 & $\begin{array}{l}0,35 \\
\text { (IVcat.) }\end{array}$ \\
\hline & & & Solvent naphtha & 804,0 & 0,147 & 81,66 & $\begin{array}{l}0,2 \\
\text { (IVcat.) }\end{array}$ \\
\hline & & & Paint aerosol & 555,75 & 0,1 & 55,56 & - \\
\hline
\end{tabular}

Based on the obtained data, the necessary degree of purifying from all types of contamination of the machine assembly department was calculated.

To do this, the emission of various pollutants through the exhaust system was determined and the norms and conditions for their release were calculated. The discharge conditions are determined by the height of the release point above the ground for the discharge points.

The minimum height of the release point above the ground is calculated by the following formula: 


$$
\mathrm{H}=\left[\frac{A \cdot G \cdot F \cdot D \cdot \eta}{8 \cdot Q \cdot(M P C O T-C b)}\right]^{3 / 4} \text {, where }
$$

A - a coefficient that depends on the temperature stratification of the atmosphere. Its value corresponds to adverse weather conditions, in which the concentration of harmful substances in the atmosphere is maximum. For the central part of Russia, $\mathrm{A}=160\left[\left(\mathrm{sec}^{2 / 3} \mathrm{mg} \mathrm{gr}^{1 / 3}\right) / 2\right]$;

$\mathrm{G}$ - mass of harmful substance released into the atmosphere per unit of time, $\mathrm{g} / \mathrm{sec}$;

$\mathrm{F}$ - non-dimentional coefficient that takes into account the rate of harmful substance settling in the atmospheric air: for gaseous substances $F=1$, for fine particles and aerosols without purifying $\mathrm{F}=3$;

$\mathrm{D}$ - diameter of the release point, $\mathrm{m}$;

$\eta$ - a non-dimentional coefficient that takes into account the influence of terrain features, in the case of flat or slightly intersected terrain with a height difference of no more than 50 m per $1 \mathrm{~km}, \eta=1$.

$\mathrm{Q}$ - flow rate of the gas-air mixture ejected through the release point, $\mathrm{m}^{3} / \mathrm{sec}$;

MPC OT - maximum permissible one-time concentration, $\mathrm{mg} / \mathrm{m}^{3}$;

$\mathrm{Cb}$ - background concentration of the pollutant in the air created by other sources, excluding this one, $\mathrm{mg} / \mathrm{m}^{3}$;

The diameter is calculated by the formula:

$$
D=\sqrt{\frac{4 Q}{\pi \cdot w_{0}},}
$$

where $\mathrm{w}_{0}$ is the average rate of the gas-air mixture release,

$w_{0} \leq 18 \mathrm{~m} / \mathrm{sec}$.

1 Release point:

$$
\mathrm{D}_{1}=\sqrt{\frac{4 \cdot 5,03}{3,14 \cdot 18}}=0,6 \mathrm{~m} .
$$

When the purifying level is $0 \%$, we find the pipe heights for the following substances:

Abrasive dust (invasive and metal):

$$
\begin{gathered}
G_{0}=(1-0) \cdot 0,57=0,57 \mathrm{~g} / \mathrm{sec}, \\
\mathrm{H}=\left[\frac{160 \cdot 0,57 \cdot 3 \cdot 0,6 \cdot 1}{8 \cdot 5,03 \cdot(0,04-0,00004)}\right]^{3 / 4}=32,11 \mathrm{~m} ;
\end{gathered}
$$

Oil and emulsifier vapours:

$$
\begin{gathered}
G_{0}=(1-0) \cdot 0,00061=0,00061 \mathrm{~g} / \mathrm{sec}, \\
\mathrm{H}=\left[\frac{160 \cdot 0,00061 \cdot 3 \cdot 0,6 \cdot 1}{8 \cdot 5,03 \cdot(5-0,005)}\right]^{3 / 4}=0,005 \mathrm{~m} ;
\end{gathered}
$$

Abrasive dust (invasive and metal) with a purifying degree of $60 \%$ :

$$
\begin{gathered}
G_{0}=(1-0,6) \cdot 0,57=0,228 \mathrm{~g} / \mathrm{sec}, \\
\mathrm{H}=\left[\frac{160 \cdot 0,228 \cdot 3 \cdot 0,6 \cdot 1}{8 \cdot 5,03 \cdot(0,04-0,00004)}\right]^{3 / 4}=16,15 \mathrm{~m} ;
\end{gathered}
$$

with a purifying degree of $80 \%$ : 


$$
\begin{aligned}
& G_{0}=(1-0,8) \cdot 0,57=0,114 \mathrm{~g} / \mathrm{sec}, \\
& \mathrm{H}=\left[\frac{160 \cdot 0,114 \cdot 3 \cdot 0,6 \cdot 1}{8 \cdot 5,03 \cdot(0,04-0,00004)}\right]^{3 / 4}=9,61 \mathrm{~m} ;
\end{aligned}
$$

with a purifying degree of $90 \%$ :

$$
\begin{aligned}
& G_{0}=(1-0,9) \cdot 0,57=0,057 \mathrm{~g} / \mathrm{sec}, \\
& \mathrm{H}=\left[\frac{160 \cdot 0,057 \cdot 3 \cdot 0,6 \cdot 1}{8 \cdot 5,03 \cdot(0,04-0,00004)}\right]^{3 / 4}=5,71 \mathrm{~m} ;
\end{aligned}
$$

We calculate the value of the dangerous speed and perform a condition check:

$$
v=1,3 \frac{\omega_{0} \cdot D}{\mathrm{H}_{\mathrm{T}}}=1,3 \frac{18 \cdot 0,6}{5,71}=2,46 \mathrm{~m} / \mathrm{sec}>2 \mathrm{~m} / \mathrm{sec}
$$

Therefore, we get the height of the source NTR $2=5.71 \mathrm{~m}$.

2 Release point:

$$
\mathrm{D}_{2}=\sqrt{\frac{4 \cdot 1,8}{3,14 \cdot 18}}=0,36 \mathrm{~m}
$$

When the purifying level is $0 \%$, we find the pipe heights for the following substances:

Butyl acetate:

$$
\mathrm{H}=\left[\frac{160 \cdot 0,023 \cdot 1 \cdot 0,36 \cdot 1}{8 \cdot 1,8 \cdot(0,1-0,0001)}\right]^{3 / 4}=0,94 \mathrm{~m}
$$

Acetone:

$$
\mathrm{H}=\left[\frac{160 \cdot 0,085 \cdot 1 \cdot 0,36 \cdot 1}{8 \cdot 1,8 \cdot(0,35-0,00035)}\right]^{\frac{3}{4}}=0,98 \mathrm{~m}
$$

Solvent naphtha:

$$
\mathrm{H}=\left[\frac{160 \cdot 0,147 \cdot 1 \cdot 0,36 \cdot 1}{8 \cdot 1,8 \cdot(0,2-0,0002)}\right]^{\frac{3}{4}}=2,25 \mathrm{~m} .
$$

Paint spray is released without purifying.

Now we calculate the value of the dangerous speed:

$$
\begin{aligned}
& v=1,3 \cdot \frac{\omega_{O} \cdot D}{H}=1,3 \cdot \frac{18 \cdot 0,5}{1,71}=6,84 \mathrm{~m} / \mathrm{sec}, \\
& v=1,3 \cdot \frac{\omega_{O} \cdot D}{H}=1,3 \cdot \frac{18 \cdot 0,36}{2,25}=3,7 \mathrm{~m} / \mathrm{sec}
\end{aligned}
$$

Since $U>2 \mathrm{~m} / \mathrm{sec}$, we take the final value of the pipe height $\mathrm{Np} 2=2.25 \mathrm{~m}$.

The obtained data and the data for calculating the air emission of various pollutants through the exhaust system are presented in table 2 . 
Table 2. Calculation of the required level of emission purifying

\begin{tabular}{|c|c|c|c|c|}
\hline $\begin{array}{l}\text { Releas } \\
\text { e point }\end{array}$ & $\begin{array}{l}\text { Name of the } \\
\text { pollutant }\end{array}$ & $\begin{array}{l}\text { The height of } \\
\text { the release } \\
\text { point, } \mathrm{Hp}, \mathrm{m}\end{array}$ & $\begin{array}{c}\text { Air emission } \\
\text { purification } \\
\text { degree, } \\
\delta, \%\end{array}$ & $\begin{array}{c}\text { The accepted value of } \\
\text { the pipe height, Hp, m, } \\
\text { and the degree of } \\
\text { purifying, } \delta, \%\end{array}$ \\
\hline \multirow{5}{*}{$\mathbf{I}$} & Abrasive-metal dust & 32.11 & \multirow[b]{2}{*}{$0 \%$} & \multirow{5}{*}{$\begin{array}{c}\mathrm{H}=5.71 \mathrm{~m} . \\
\mathrm{D}=0.6 \mathrm{~m} . \\
\omega=18 \mathrm{~m} / \mathrm{sec} . \\
\delta=90 \%-\text { abrasive- } \\
\text { metal dust } \\
\delta=90 \% \text { - oil vapour } \\
\text { and emulsifier }\end{array}$} \\
\hline & $\begin{array}{c}\text { Oil vapour and } \\
\text { emulsifier }\end{array}$ & 0.005 & & \\
\hline & Abrasive-metal dust & 16.15 & $60 \%$ & \\
\hline & Abrasive-metal dust & 9.61 & $80 \%$ & \\
\hline & Abrasive-metal dust & 5.71 & $90 \%$ & \\
\hline \multirow{3}{*}{ II } & Butyl acetate & 0.94 & \multirow{3}{*}{$90 \%$} & \multirow{3}{*}{$\begin{array}{c}\mathrm{H}=2.25 \mathrm{~m} . \\
\mathrm{D}=0.36 \mathrm{~m} . \\
\omega=18 \mathrm{~m} / \mathrm{sec} \\
\delta=90 \% \text { for all } \\
\text { substances }\end{array}$} \\
\hline & Acetone & 0.98 & & \\
\hline & Solvent naphtha & 2.25 & & \\
\hline
\end{tabular}

Based on the calculations, the necessary equipment was selected - Cyclone CVP 10 for emission points 1 and 2, which will provide the necessary degree of protection from harmful effects on the atmosphere. Its main characteristics are shown in table 3.

Table 3. Equipment specifications.

\begin{tabular}{|c|c|c|c|c|c|c|c|}
\hline \multirow{2}{*}{ 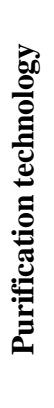 } & \multirow{2}{*}{ 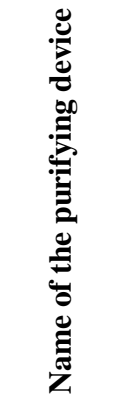 } & \multirow[b]{2}{*}{ 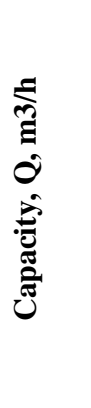 } & \multirow[b]{2}{*}{ 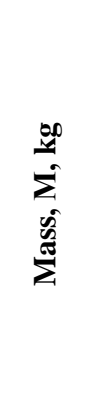 } & \multirow{2}{*}{ 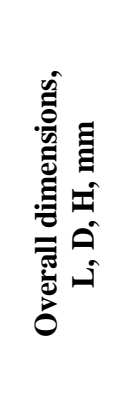 } & \multirow{2}{*}{ 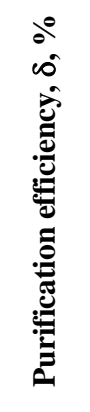 } & \multicolumn{2}{|c|}{$\begin{array}{c}\text { Comparative } \\
\text { indicators }\end{array}$} \\
\hline & & & & & & 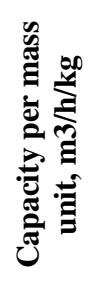 & 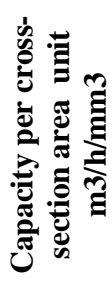 \\
\hline 1 & $\begin{array}{l}\text { Cyclone } \\
\text { CVP } 10\end{array}$ & $\begin{array}{l}\mathrm{Qn}=2 \\
0000\end{array}$ & 569.5 & $\begin{array}{l}1513 * 10 \\
00 * 7044\end{array}$ & $95-99$ & 35.11 & 1592 \\
\hline
\end{tabular}

It is necessary to select the correct fan for the equipment [17]. To select the fan, an aerodynamic calculation of the exhaust ventilation system was made. To do this, a diagram of the exhaust system is drawn in axonometric perspective, the sections are numbered, the length and amount of air that should be supplied through each section is specified. Due to calculations, it was determined: for the first release point, the radial fan VR 80-75№8 with capacity up to $23000 \mathrm{~m}^{3} / \mathrm{h}$ and pressure loss of $1440 \mathrm{~Pa}$. must be installed, for the second release point, the fan, VR 80-75№6,3 with capacity up to $17500 \mathrm{~m}^{3} / \mathrm{h}$ and pressure loss 1200 Pa. must be installed.

Due to the implementation of environmental measures, such as designed engineering protection of the atmosphere, the company increases its profit $[18,19]$. Let us calculate the amount of prevented economic damage. 
Table 4. The initial data for calculations.

\begin{tabular}{|c|c|c|c|}
\hline Pollutants & $\begin{array}{c}\text { Mass before } \\
\text { purification, } \\
\text { mi, t/year }\end{array}$ & $\begin{array}{c}\text { Mass after } \\
\text { purification, } \\
\text { mi, t/year }\end{array}$ & $\begin{array}{c}\text { Indicators of relative } \\
\text { aggressiveness of the i- } \\
\text { type impurity, } \mathbf{A}_{\boldsymbol{i}} \text {, } \\
\text { conv. th/t }\end{array}$ \\
\hline Butyl acetate & 0.13 & 0.01 & 41.5 \\
\hline Acetone & 0.36 & 0.04 & 6 \\
\hline Solvent naphtha & 0.8 & 0.08 & 60 \\
\hline Abrasive-metal dust & 2.81 & 0.28 & 3 \\
\hline Oil vapour & 0.02 & 0.0019 & 5 \\
\hline Paint aerosol & 0.56 & 0.06 & \\
\hline
\end{tabular}

1. Calculate the reduced mass of discharges, $t$ /year:

$$
M=m_{1} \cdot A_{1}+m_{2} \cdot A_{2},
$$

where $m_{i}-$ mass of the annual release of the $i$-type impurity into the atmosphere, $t$ /year;

$\mathrm{Ai}$ - indicator of relative aggressiveness of the $\mathrm{i}$-type impurity, $\mathrm{t} / \mathrm{t}$

Reduced mass of pollutant discharges before purification:

$\mathrm{M}_{1}=0,13 \cdot 41,5+0,36 \cdot 6+0,8 \cdot 41,1+2,81 \cdot 60+0,02 \cdot 3+0,56 \cdot 5=212 \mathrm{t} /$ year

Reduced mass of pollutant discharges after purification:

$M_{2}=0,01 \cdot 41,5+0,04 \cdot 6+0,08 \cdot 41,1+0,28 \cdot 60+0,0019 \cdot 3+0,6 \cdot 5$

$$
=23,75 \mathrm{t} / \text { year }
$$

2. Calculate the damage before and after the environmental measures, RUB/year:

$$
\mathrm{U}=\gamma \cdot \sigma \cdot \mathrm{f} \cdot \mathrm{M}
$$

where $\gamma=49$ RUB/conv. $t-$ specific damage value;

$\sigma=4-$ indicator of the relative danger of air pollution over territories;

$\mathrm{f}=1-$ coefficient that takes into account the dispersion of emissions into the atmosphere;

$\mathrm{M}$ - the reduced mass of the annual air emission in the machine assembly department, conv. t/year,

Damage before the environmental measures implementation:

$$
\mathrm{D}=49 \cdot 4 \cdot 1 \cdot 212=41552 \mathrm{RUB} / \text { year; }
$$

Damage after the environmental measures implementation:

$$
\mathrm{D}^{\prime}=49 \cdot 4 \cdot 1 \cdot 23,75=4655 \mathrm{RUB} / \text { year; }
$$

3. The amount of the prevented economic damage will be:

$$
\mathrm{R}=\mathrm{P}=\left(\mathrm{U}_{1}-\mathrm{U}_{2}\right) \cdot \mathrm{k}_{4},
$$

where $\left(U_{1}-U_{2}\right)$ - the difference between the damage amount before and after the implementation of environmental measures

$\mathrm{k}_{4}=3,65-$ coefficient that takes into account inflation,

$$
\mathrm{R}=\mathrm{P}=(41552-4655) \cdot 3,65=134674,05 \mathrm{RUB} / \mathrm{year}
$$


Table 5. Calculation results from the implementation of engineering protection of the atmosphere.

\begin{tabular}{|c|l|c|}
\hline No. & \multicolumn{1}{|c|}{ Indicator name } & Numerical value, RUB/year \\
\hline 1 & Environmental damage before the purification & 41552 \\
\hline 2 & Environmental damage after the purification & 4655 \\
\hline 3 & Prevented damage & 134674 \\
\hline
\end{tabular}

\section{Conclusions}

As a result of calculations and the development of the purifying systems, the introduction of purification facilities contributed not only to a significant reduction of pollutants in the air, but also to savings due to lack of emissions.

\section{References}

1. B. Kauder, N. Potrafke, W. Heinrich, European Journal of Political Economy 54, 26-41 (2018)

2. O.V. Petko, Rossiyskoe predprinimatelstvo 13(7), $10-14 \quad$ (2012) url: https://creativeconomy.ru/lib/7406

3. R.N. Salieva, V.Z. Latypova, I.R. Saliev, Theoretical and Applied Ecology 3, 142-148 (2019) DOI: 10.25750/1995-4301-2019-3-142-148

4. P.V. Pisarenko, M.S. Samoilik, I.L. Plaksienko, L.A. Kolesnikova, Theoretical and applied ecology 2, 137-142 (2019) DOI: 10.25750/1995-4301-2019-2-137-142

5. M.F. Zamyatina, Economics and Management 3, 23-31 (2019) https://emjume.elpub.ru/jour/article/view/610

6. N.V. Bouguereau, S.M. Alexandrov, N.A. Ilyin, Problems of Regional Ecology 33, 6 (2019) DOI: 10.24411/1728-323X-2019-18033

7. I.A. Gorkova, A.V. Miklyaeva, Azimuth of Scientific Research: Pedagogy and Psychology 4(29), 8 (2019) DOI: 10.26140/anip-2019-0804-0080

8. T.A. Meshchurova, M.B. Khodyashev, S.A. Varyukhina, A.D. Nozdryukhin, Problems of regional ecology 4 (2019) DOI: 10.24411/1728-323X-2019-14015

9. M.V. Panarin, N.A. Rybka, A.A. Maslova, V.V. Sergeev, I.Yu. Zagumennov, Measurement. Monitoring Control. Control 4(30) (2019) DOI 10.21685/2307-55382019-4-2

10. A.D. Zelepugin, Actual directions of scientific research of the XXI century: theory and practice 2(5-3)(10-3), 469-476 (2012) DOI: 10.12737/7029

11. M.V. Mukhina, S.M. Shevchenko, K.A. Frolova, Waste and resources 5(1), 7 -10 (2018) DOI: $10.15862 / 08$ NZOR118

12. J. Curtis, S. Kaufman, Journal of Environmental Management 26215, 110336 (2020)

13. S. E. Mbuligwe, Encyclopedia of Environmental Health, 486-495 (2019)

14. V.G. Gladkikh, T.V. Danilova, Azimuth of Scientific Research: Pedagogy and Psychology 3(28), 79-82 (2019) DOI: 10.26140/anip-2019-0803-0019

15. L.N. Safullin, A.F. Mingazova, Economics and Management 3, 54-61 (2019) https://emjume.elpub.ru/jour/article/view/617

16. H. Duan, L. Cui, J. Song, L.X. Zhang, Zh. Duan, Journal of Cleaner Production 2421, 118489 (2020) 
17. Zh. Cao, C. Zhai, Y. Wang, T. Zhao, H.W. Wang, Sustainable Cities and Society 54, 101990 (2020)

18. S.Yu. Shaposhnikova, Russian Journal of Entrepreneurship 12(1), 54-59 (2011) url: https://creativeconomy.ru/lib/6585

19. S.Yu. Shaposhnikova, Russian Entrepreneurship 1, 54-60 (2011) https://rucont.ru/efd/540290 